\title{
Estudo da viabilidade do uso de resíduo de polimento de rochas ornamentais em porcelanas
}

\author{
Study the feasibility of using natural stone \\ polishing residue in porcelain
}

Adriana Scoton Antonio Chinelatto ${ }^{1}$, Adilson Luiz Chinelatto ${ }^{1}$, Dannilo Eduardo Munhoz Ferreira ${ }^{1}$, Guilherme Gralik ${ }^{1}$

${ }^{1}$ Departamento de Engenharia de Materiais/UEPG, Grossa Av. Carlos Cavalcanti 4748 CEP 84030-900 Ponta Grossa - PR.
${ }^{1}$ email: adriana@uepg.br, adilson@uepg.br, danniloeduardo@hotmail.com, guilherme_gralik@yahoo.com.br

\begin{abstract}
RESUMO
Porcelanas são cerâmicas multifásicas produzidas a partir de matérias-primas naturais e utilizadas na fabricação de uma grande variedade de produtos. Este trabalho teve como objetivo verificar a viabilidade da substituição total e parcial do feldspato presente na formulação de porcelanas, por resíduo de rochas ornamentais oriundo do processo de polimento de uma empresa de médio porte. As matérias-primas selecionadas foram cominuídas em moinho de bolas a úmido e posteriormente peneiradas em malha 80 mesh. Foram realizadas análises de fluorescência de raios $\mathrm{X}$, difração de raios $\mathrm{X}$, microscopia eletrônica de varredura e também distribuição de tamanho de partículas. Para avaliar os efeitos desta substituição foram formuladas quatro composições variando a quantidade de resíduo em substituição ao feldspato, nestas amostras foram feitas análises de distribuição de tamanho de partículas, posteriormente os corpos de prova foram prensados e sinterizados em temperaturas que variaram de 1100 a $1250^{\circ} \mathrm{C} \mathrm{em}$ forno elétrico resistivo com patamar de 2 horas. A caracterização das porcelanas foi feita por medidas de porosidade aparente, absorção de água e densidade aparente pelo método de Arquimedes, também foram realizadas medidas de resistência mecânica feita por flexão em três pontos, difração de raios X para a análise das fases formadas e microscopia eletrônica de varredura para a análise microestrutural. Os resultados mostraram que é viável a substituição do feldspato por resíduo de polimento de rochas ornamentais, uma vez que as propriedades físicas das porcelanas como absorção de água e resistência mecânica são pouco alteradas. Além disso, a adição de resíduo diminui as temperaturas necessárias para sinterização, sendo no entanto, necessário, ter maior controle dessa temperatura no processo produtivo, devido ao menor intervalo de queima.
\end{abstract}

Palavras-chave: porcelana, resíduo de rochas ornamentais, feldspato.

\begin{abstract}
Porcelains are multiphase ceramics produced from natural raw materials and used in manufacturing a wide variety of products. This study aimed to verify the feasibility of the total and partial replacement of feldspar present in the formulation of porcelain by ornamental stones residue coming from the polishing process of a medium-sized company. The materials selected were comminuted in the wet ball mill and subsequently sieved through 80 mesh Fluorescence X-ray analysis, scanning electron microscopy and also particle size distribution were made. They were formulated four compositions by varying the amount of residue replacing feldspar. In these samples the particle size distribution analyzes were performed and subsequently the samples were pressed and sintered at temperatures ranging from 1100 to $1250^{\circ} \mathrm{C}$ in resistive electric oven for 2 hours. The porcelains characterizations were made by apparent porosity, water absorption and apparent density by the Archimedes method; mechanical resistance measurements were also performed made by bending at three points; X-ray diffraction for the analysis of the phases, and scanning electron microscopy for microstructural analysis. The results showed that it is feasible to replace the feldspar for ornamental rocks polishing residue, since the physical properties of the porcelain as water absorption and mechanical strength and are slightly changed. Furthermore, the addition of residue reduces the sintering temperature, however, it
\end{abstract}


is necessary to have greater control of this temperature in the production process due to the lower firing range.

Keywords: porcelain, ornamental stones residue, feldspar.

\section{INTRODUÇÃO}

Estima-se que cerca de 15 bilhões de toneladas de matérias-primas sejam anualmente extraídas em âmbito mundial, sendo algumas renováveis, mas uma grande parte delas não. Com o passar do tempo, tornou-se real a consciência de que os recursos são finitos, sendo premente a sua utilização racional, reutilização e reciclagem [1].

O aproveitamento dos resíduos industriais para o uso como matérias-primas alternativas na indústria cerâmica já vem sendo estudado e utilizado há algum tempo [2]. O uso específico de resíduo proveniente da indústria de rochas ornamentais também vem sendo analisado para a sua incorporação em uma série de produtos cerâmicos como: concretos [3], alvenaria de vedação [4], argamassa de revestimento, lajotas para pisos [5], grés-porcelanatos [6], blocos para contenção de talude [7], lã mineral [8], telhas [9]. Os resultados mostram que a heterogeneidade dos produtos cerâmicos tradicionais permite a incorporação de uma quantidade razoável desses resíduos sem prejuízo das propriedades dos produtos finais [10].

O potencial da utilização de resíduo de beneficiamento de rochas ornamentais se deve ao fato do Brasil ser um grande exportador deste produto, sendo o $8^{\circ}$ país em exportação de blocos e o $5^{\circ}$ maior exportador de rochas ornamentais acabadas. Atualmente, o mercado de rochas ornamentais movimenta no país cerca de 2,1 bilhões de dólares por ano [11]. Existem no Brasil cerca de 780 empresas dos mais variados portes, onde o estado do Espírito Santo detém cerca de 50\% da capacidade produtiva [12].

Nesta indústria de beneficiamento de rochas ornamentais, as diversas etapas de produção geram grandes perdas, com um volume de resíduo bastante significativo. Apesar de existir uma preocupação com o meio ambiente, na maioria das vezes, o resíduo é jogado diretamente no ecossistema sem nenhum tratamento prévio. As lamas geradas nesse processo não são consideradas um resíduo perigoso, mas constituem um problema ambiental [13,14]. Algumas empresas acumulam o resíduo em tanques de contenção durante vários anos de operação, como é o caso da empresa de onde o resíduo utilizado neste trabalho foi obtido.

No processo de extração e beneficiamento de rochas ornamentais são gerados vários tipos de resíduos, que são: o resíduo de extração dos blocos, resíduos da serragem para enquadrá-los nas dimensões padrões e o resíduo do processo de serragem e polimento, este último enquadra em basicamente três subtipos: o resíduo de mármore, resíduo de granito e resíduo de mármore e granito do qual trata este trabalho [3].

O granito é uma rocha ígnea, constituída principalmente por feldspatos, quartzo e micas [12], sendo o feldspato o mineral predominante. Existem granitos brancos, leitosos, róseos, amarelados e cinzentos [3]. Os mármores são rochas metamórficas formadas pela recristalização do calcário a altas temperaturas e pressões, pode apresentar cores variadas como branca, rosácea, esverdeada e preta, entre os minerais que o compõem estão o feldspato e a mica [3].

Em geral os resíduos de rochas ornamentais apresentam um comportamento não plástico tal como a grande maioria dos materiais cerâmicos tradicionais e seus constituintes químicos majoritários, expressos na forma de óxidos, são a sílica $\left(\mathrm{SiO}_{2}\right)$, alumina $\left(\mathrm{Al}_{2} \mathrm{O}_{3}\right)$, óxido de cálcio $(\mathrm{CaO})$ e os óxidos alcalinos $\left(\mathrm{Na}_{2} \mathrm{O}\right.$, $\left.\mathrm{K}_{2} \mathrm{O}\right)[13,14]$.

A presença de feldspato na constituição mineralógica das rochas ornamentais é um fator que viabiliza o seu uso em formulações de porcelanas triaxiais. As porcelanas são materiais multifásicos produzidos com matérias-primas naturais (quartzo-feldspato-caulim) e são utilizadas na fabricação de uma grande variedade de produtos cerâmicos, devido ao baixo custo de suas matérias-primas [15].

O objetivo deste trabalho foi avaliar a viabilidade da substituição do feldspato pelo resíduo de polimento das rochas ornamentais na formulação de porcelanas triaxiais através da caracterização física, química e microestrutural dos produtos.

\section{MATERIAIS E MÉTODOS}

As matérias-primas selecionadas para o trabalho foram: Feldspato Mark, Argila Gnatta, Quartzito, Caulim Hori e resíduo de polimento de rochas ornamentais. O resíduo de rochas ornamentais foi coletado numa empresa localizada nos Campos Gerais, PR. Esse resíduo é proveniente da etapa de polimento final dessas rochas.

Inicialmente, as matérias-primas em estado bruto foram desaglomeradas em almofariz com pistilo de porcelana, os pós resultantes foram moídos a úmido em moinho de bolas convencional na proporção 2:1, por 
4 horas. As barbotinas obtidas foram colocadas em estufa, a $105^{\circ} \mathrm{C}$, por 24 horas. Após esse período, as matérias-primas foram desaglomeradas e peneiradas em peneira malha 80 mesh.

As matérias-primas foram então caracterizadas por fluorescência de raios X (Shimadzu EDX-700) e por difração de raios X (Shimadzu modelo XRD-6000), utilizando uma velocidade de varredura de $2 \%$ min e variando $2 \theta$ de 5 a $90^{\circ}$, os difratogramas foram identificados utilizando-se a base do programa Match Phase Identification from Powder Difraction versão 2.0.

Nas amostras de feldspato e do resíduo das rochas ornamentais foram realizadas também análises por microscopia eletrônica de varredura (Shimadzu, modelo SSX-550), para analisar a morfologia das partículas e de distribuição de tamanho de partículas (granulômetro Cilas, modelo 920).

Foram formuladas quatro composições de acordo com a Tabela 1, nas quais o feldspato foi substituído pelo resíduo de rochas ornamentais parcialmente e totalmente. A composição 4 é uma formulação tipicamente utilizada na fabricação de isoladores elétricos.

Tabela 1: Composições estudadas.

\begin{tabular}{c|c|c|c|c|c}
\hline COMPOSIÇÃO (\%) & ARGILA & QUARTZO & CAULIM & FELDSPATO & PÓ DE GRANITO \\
\hline 1 & 10 & 30 & 25 & 25 & 10 \\
\hline 2 & 10 & 30 & 25 & 10 & 25 \\
\hline 3 & 10 & 30 & 25 & - & 35 \\
\hline 4 & 10 & 30 & 25 & 35 & - \\
\hline
\end{tabular}

Após a pesagem das matérias-primas nas proporções apresentadas na Tabela 1, as composições foram homogeneizadas em moinho de bolas a úmido, utilizando $1 \%$ de silicato de sódio como defloculante, por um período de 4 horas. Após a homogeneização, as barbotinas foram secas em estufa por 24 horas a $105^{\circ} \mathrm{C} \mathrm{e}$ posteriormente desaglomeradas e peneiradas em peneira malha 80 mesh, e armazenadas em sacos plásticos com 5\% em peso de água por 24 horas para facilitar na conformação dos corpos de prova. Nas amostras das composições homogeneizadas foram realizadas análises de distribuição de tamanho de partícula (Cilas, modelo 920).

Os corpos de prova foram conformados na forma de pequenas barras retangulares por prensagem uniaxial, em prensa hidráulica com $80 \mathrm{MPa}$ de tensão de compactação, em molde metálico. Os corpos de prova foram sinterizados nas seguintes temperaturas: $1100^{\circ} \mathrm{C}, 1150^{\circ} \mathrm{C}, 1200^{\circ} \mathrm{C}$ e $1250^{\circ} \mathrm{C}$ com taxa de aquecimento de $10^{\circ} \mathrm{C} / \mathrm{min}$. e com patamar na temperatura máxima por duas horas.

Após a sinterização, os corpos de prova foram caracterizados por medidas de porosidade aparente, absorção de água e densidade aparente feita pelo método de Arquimedes (água destilada, $21^{\circ} \mathrm{C}$ ), e por medidas de resistência mecânica, feita por flexão em três pontos em uma máquina de ensaios universal modelo Shimadzu Autograph AGS com carga máxima de $10 \mathrm{kN}$.

Para avaliar as fases formadas no processo de sinterização foram realizadas análises de difração de raios X (Shimadzu modelo XRD-6000) utilizando uma velocidade de varredura de $2 \%$ min e variando $2 \theta$ de 5 a $90^{\circ}$, os difratogramas foram identificados utilizando-se a base do programa Match Phase Identification from Powder Difraction versão 2.0. Para obtenção das micrografias, as amostras sinterizadas foram lixadas, polidas e atacadas com ácido fluorídrico $5 \%$, por 15 segundos, para revelar as microestruturas, então os corpos de prova foram lavados em ultrassom e secos em estufa, a $105^{\circ} \mathrm{C}$. Foi feito o recobrimento das amostras pelo método de sputtering, para formação de uma fina camada de ouro na superfície de observação em um equipamento de recobrimento a plasma, marca Shimadzu, modelo Ion Coater IC-50 e obtidas as imagens em um microscópio Shimadzu, modelo SSX-550.

\section{RESULTADOS E DISCUSSÃO}

A Tabela 2 apresenta os elementos químicos presentes nas matérias-primas utilizadas, determinados por fluorescência de raios X (FRX). Pela análise química das matérias-primas apresentadas na Tabela 2, pode-se observar que em todas elas, o $\mathrm{SiO}_{2}$ é o óxido predominante, seguido pelo $\mathrm{Al}_{2} \mathrm{O}_{3}$. O resíduo das rochas ornamentais apresenta uma quantidade significante de ferro e embora este esteja expresso em termos de $\mathrm{Fe}_{2} \mathrm{O}_{3}$, alguns desses ferros presentes consistem de partículas finas, abrasivas provenientes do processo de corte, polimento dos blocos e o posterior transporte do resíduo. A presença da alta quantidade de óxido de 
cálcio $(\mathrm{CaO})$ neste resíduo pode ser atribuída ao feldspato presente nas rochas de granito e também à composição do mármore. $\mathrm{O}$ resíduo também exibe uma alta quantidade de óxidos fundentes $\left(\mathrm{CaO}, \mathrm{K}_{2} \mathrm{O}\right.$ e $\mathrm{Fe}_{2} \mathrm{O}_{3}$ ), que promovem a formação da fase líquida em menor temperatura e com menor viscosidade [15].

Tabela 2: Composição química das matérias-primas (\% em peso).

\begin{tabular}{|c|c|c|c|c|c|}
\hline OXIDOS & ARGILA & QUARTZO & CAULIM & FELDSPATO & $\begin{array}{c}\text { RESÍDUO DE ROCHAS } \\
\text { ORNAMENTAIS }\end{array}$ \\
\hline $\mathrm{Al}_{2} \mathrm{O}_{3}$ & 25,91 & 22,40 & 49,62 & 26,20 & 11,89 \\
\hline $\mathrm{SiO}_{2}$ & 66,02 & 75,64 & 46,76 & 48,01 & 60,48 \\
\hline $\mathrm{Fe}_{2} \mathrm{O}_{3}$ & 3,13 & 0,49 & 1,46 & - & 5,54 \\
\hline $\mathrm{TiO}_{2}$ & 3,41 & - & - & - & 1,45 \\
\hline $\mathrm{K}_{2} \mathrm{O}$ & 1,11 & 1,46 & 2,44 & 20,80 & 4,96 \\
\hline $\mathrm{CaO}$ & 0,31 & - & - & - & 14,16 \\
\hline $\mathrm{MnO}$ & - & - & 0,055 & - & - \\
\hline $\mathrm{Na}_{2} \mathrm{O}$ & & & & 4,87 & \\
\hline $\mathrm{ZnO}$ & - & 0,014 & - & - & - \\
\hline $\mathrm{SO}_{3}$ & & - & - & - & 1,52 \\
\hline $\mathrm{SrO}$ & - & - & - & - & - \\
\hline
\end{tabular}

Analisando a composição química do feldspato observa-se a presença de $\mathrm{K}_{2} \mathrm{O}$, caracterizando-o como um feldspato potássico, sendo este o mais utilizado na produção de cerâmicas brancas, pois a viscosidade do líquido formado durante a sinterização é maior que os feldspatos sódicos, facilitando assim a sinterização. As demais matérias-primas apresentaram elementos químicos esperados em função da sua origem mineralógica.

A Figura 1 (a) apresenta a difração de raios $\mathrm{X}$ das matérias-primas (argila, caulim e quartzo) utilizadas, que permaneceram com proporções inalteradas nas composições formuladas e as Figuras 1 (b) e 1 (c) os difratogramas do feldspato e do resíduo de rochas ornamentais, respectivamente.

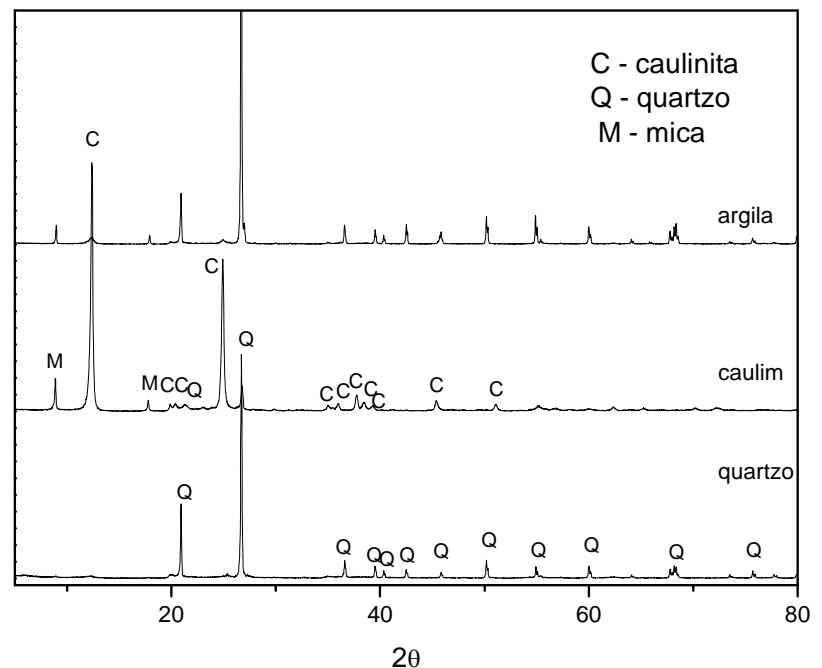

(a) 


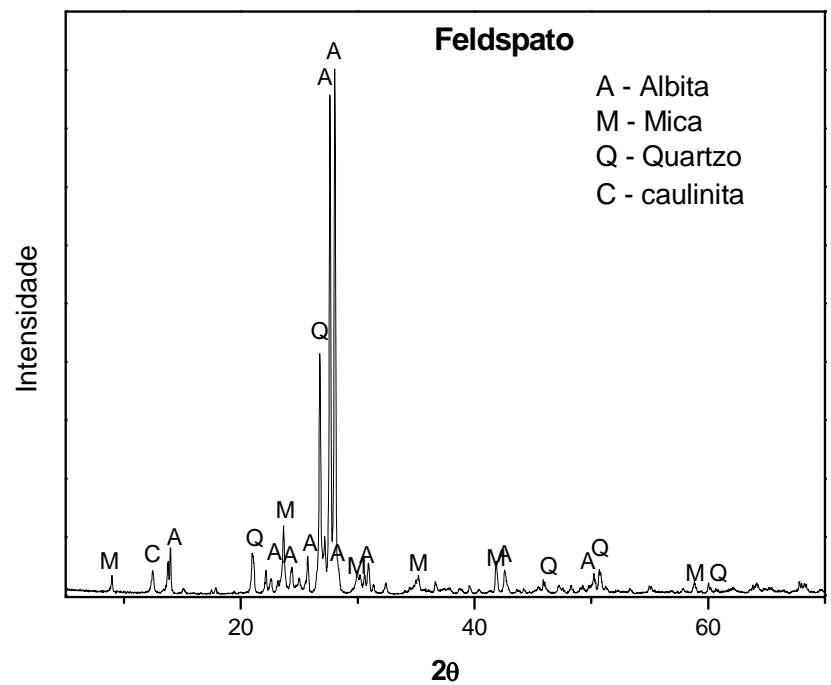

(b)

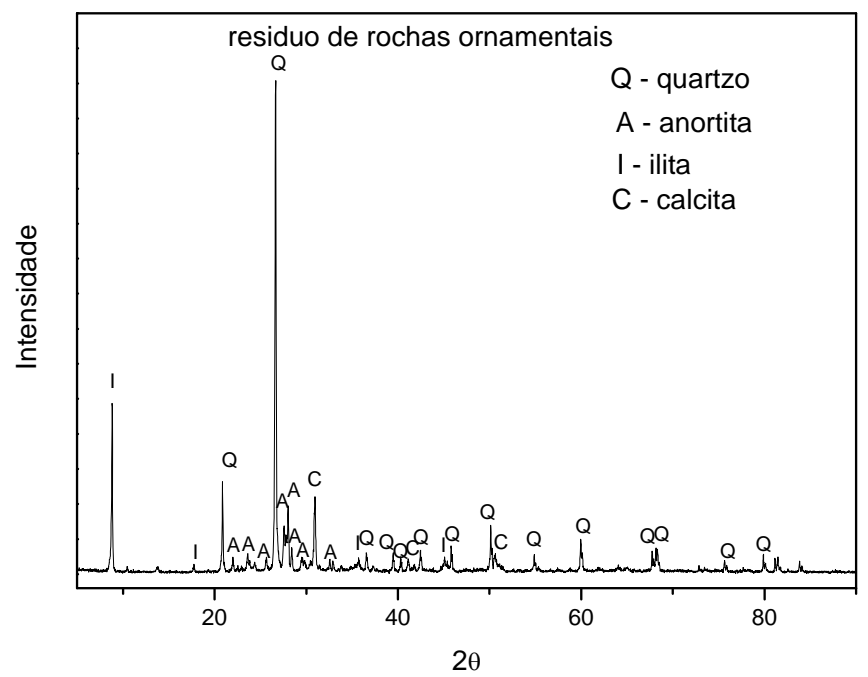

(c)

Figura 1: Difração de raios $X$ das matérias-primas utilizadas: (a) quartzo, caulim e argila; (b) feldspato e (c) resíduo de rochas ornamentais.

Observa-se na Figura 1 (a) que o caulim apresenta picos de caulinita, juntamente com alguns picos de mica e quartzo; na argila são observados picos de quartzo, caulinita e traços de mica e a amostra de quartzo apresentou apenas picos de quartzo- $\alpha$.

Na Figura 1 (b), que apresenta o difratograma do feldspato, é possível observar a presença do feldspato sódico (albita), mica, quartzo e caulinita. O resíduo de rochas ornamentais (Figura 1 (c)) apresenta como fases mineralógicas feldspato cálcico (anortita), ilita e calcita. Esses resultados confirmam a presença dos constituintes principais de rochas metamórficas do tipo gnaisse, que são ricas em feldspato e quartzo e a presença da calcita se deve ao resíduo referente ao polimento de mármores [3,12]. A presença de feldspato na composição do resíduo de rochas ornamentais garante um componente que atuará na sinterização via fase líquida agindo como fundente.

Na Figura 2 (a) pode-se observar a distribuição de tamanho das partículas do resíduo de rochas ornamentais e do feldspato e na Figura 2 (b) a distribuição de tamanho de partículas das composições de 1 a 4. Observa-se que, tanto o feldspato quanto o resíduo apresentam uma larga distribuição de tamanho de partículas, sendo que o tamanho médio de partícula do resíduo $\left(\mathrm{d}_{50}=10,41 \mu \mathrm{m}\right)$ é menor que do feldspato $\left(\mathrm{d}_{50}\right.$ $=30,37 \mu \mathrm{m})$. Como a energia de superfície aumenta com a diminuição do tamanho de partícula, ocasionando 
um aumento da reatividade, esta diferença de tamanho aumenta a reatividade do pó de resíduo de rochas ornamentais durante a sinterização em relação ao feldspato.
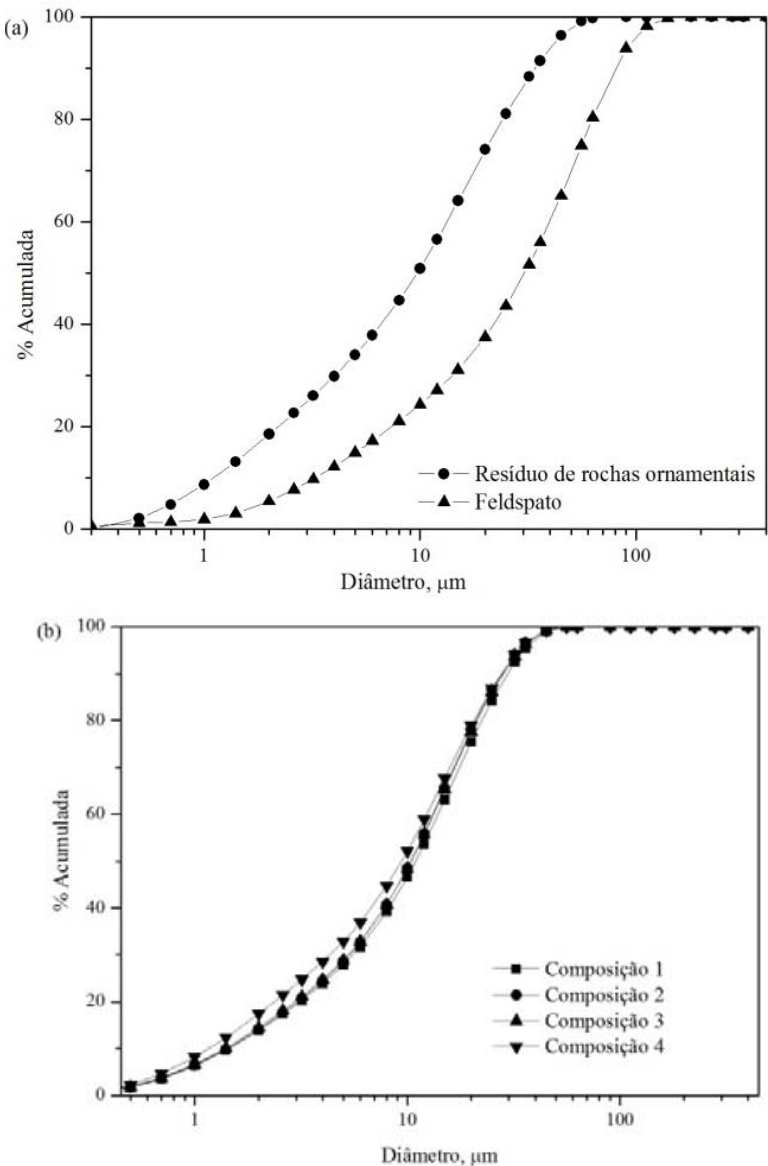

Figura 2: Distribuição de tamanho de partículas do pó de mármore e feldspato (a) e das composições de 1 a 4 (b).

As distribuições de tamanho de partícula para as composições 1, 2, 3 e 4 representadas na Figura 2 (b), apresentaram-se semelhantes, possibilitando assim uma melhor análise dos compactos e da sinterização. Os tamanhos médios de partículas $\left(\mathrm{d}_{50}\right)$ foram de $13,51 \mu \mathrm{m}$ para a composição 1 , para composição 2 foi de $12,79 \mu \mathrm{m}$, para composição 3 foi $12,88 \mu \mathrm{m}$ e finalmente de $9,38 \mu \mathrm{m}$ para a composição 4 . Durante a sinterização, a distribuição do tamanho de partículas interfere nas propriedades finais da porcelana, atuando no transporte de massa durante a densificação.

Nas Figuras 3 (a) e (b) são mostradas as micrografias dos pós de feldspato e do resíduo das rochas ornamentais, respectivamente. Pode-se observar que ambos os pós apresentam uma morfologia irregular das partículas.
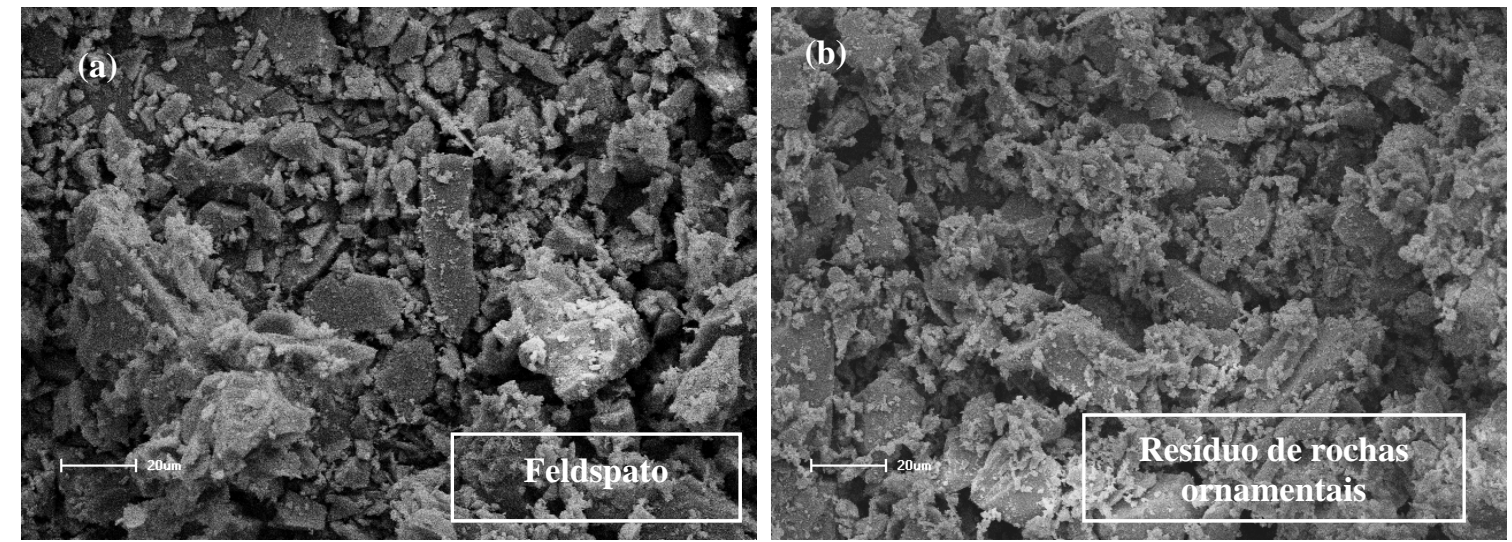

Figura 3: Micrografia dos pós de: (a) feldspato e (b) resíduos de rochas ornamentais. 
A variação da porosidade aparente e absorção de água das composições sinterizadas em diferentes temperaturas são apresentadas nas figuras 4 (a) e (b), respectivamente. Os gráficos representam os valores médios de cada propriedade obtidos para cada composição em função da temperatura de sinterização. Com o aumento de temperatura, as amostras de todas as composições estudadas apresentaram uma redução na porosidade aparente, e consequentemente uma redução nos valores de absorção de água. Os resultados de porosidade aparente e absorção de água, apresentados na Figura 4, mostram que, até na temperatura de $1150^{\circ} \mathrm{C}$, os compactos apresentaram uma porosidade elevada e uma alta absorção de água, indicando uma sinterização incompleta. Para a temperatura de sinterização de $1200^{\circ} \mathrm{C}$, as composições que contém resíduo (composições 1, 2 e 3) apresentaram uma porosidade aparente e absorção de água muito baixas, enquanto que a composição 4, que não possui resíduo em sua formulação, teve sua porosidade e absorção de água reduzida apenas na temperatura de $1250^{\circ} \mathrm{C}$. A diminuição da absorção de água e da porosidade com a temperatura está associada à diminuição da quantidade de poros abertos, resultado da densificação dos compactos.
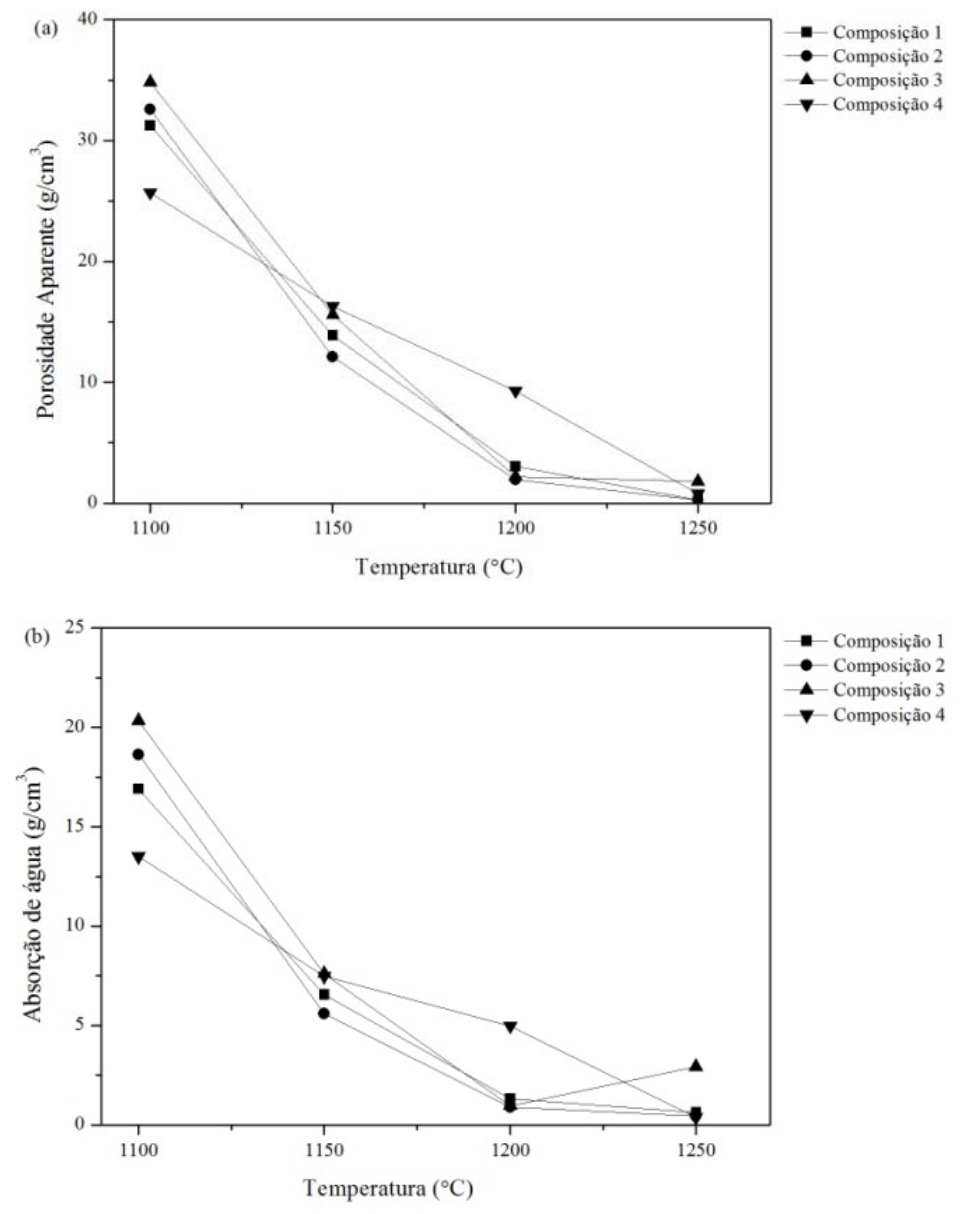

Figura 4: Variação da porosidade aparente (a), absorção de água (b).

As composições 1, 2 e 3, na temperatura de sinterização de $1250^{\circ} \mathrm{C}$, apresentaram deformação piroplástica, que é a deformação dos corpos de prova pelo efeito da temperatura. São diversos os fatores que levam à deformação piroplástica, sendo os principais fatores a quantidade, a viscosidade e a composição do líquido formado [15,16]. Na Figura 5 observa-se um conjunto de amostras das composições 1 , 2 e 3 em que foram sinterizadas a $1250^{\circ} \mathrm{C}$ e que ocorreu a superqueima.

As amostras identificadas na Figura 5 apresentam uma superfície excessivamente vitrificada e irregular, características típicas de amostras que sofreram superqueima. 


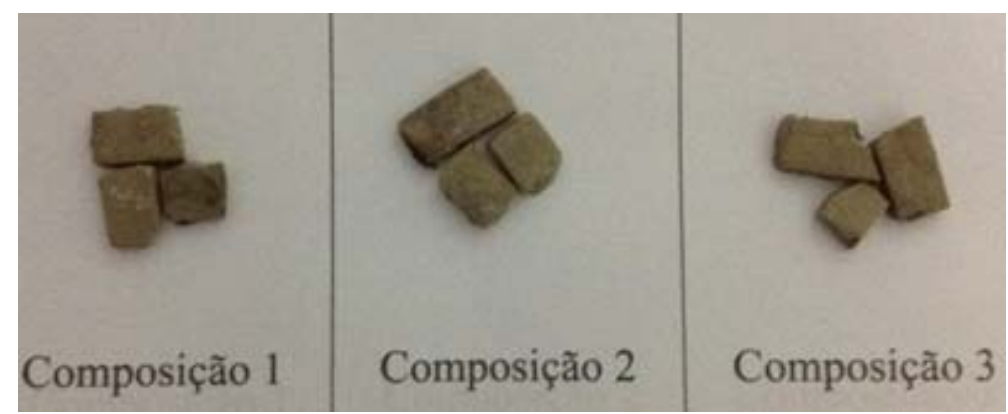

Figura 5: Fotografia dos corpos de prova das composições 1,2 e 3, na temperatura de sinterização de $1250^{\circ} \mathrm{C}$, em que ocorreu a superqueima.

As figuras 6 (a) e (b) mostram a variação da densidade aparente e resistência mecânica com a variação da temperatura de sinterização para as 4 composições, respectivamente. Nos resultados de resistência mecânica, não são apresentados os dados referentes à sinterização a $1250^{\circ} \mathrm{C}$, uma vez que, como já comentado, as amostras apresentaram deformação piroplástica.

Como pode ser observado nas Figuras 6 (a) e 4, as menores densidades e maiores porosidades aparentes e absorção de água são encontradas nas temperaturas de $1100^{\circ} \mathrm{C}$, onde os corpos de prova ainda não sofreram mudanças significativas devido a sinterização.
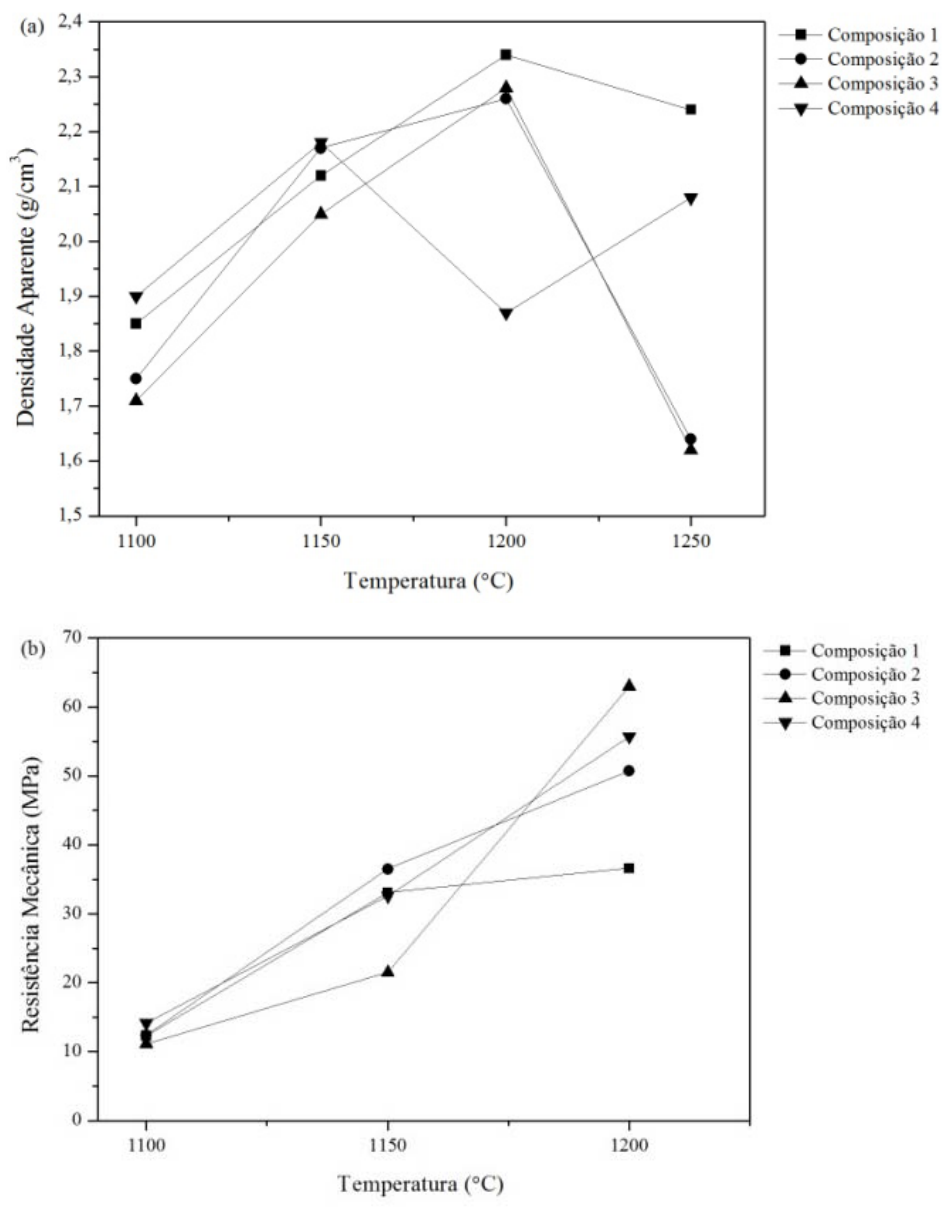

Figura 6: Variação da densidade aparente (a), resistência mecânica (b).

Conforme se pode observar na Figura 6 (a) o aumento de densidade aparente com o aumento da temperatura de sinterização, nas quatro composições indica que a sinterização por meio da formação de fase líquida, responsável pela densificação, ocorreu de forma semelhante para todas as composições. Tal 
característica se deve a sequência de reações que ocorrem na sinterização dos compactos, como a formação de fase líquida proveniente do feldspato, a decomposição do caulim e a diminuição da viscosidade da fase líquida.

A queda da densidade aparente na temperatura de $1250^{\circ} \mathrm{C}$ foi observada para as três composições que contêm resíduo de rochas ornamentais ( 1,2 e 3$)$, sendo que essa queda foi mais acentuada para as composições com maior quantidade de feldspato substituído por resíduo.

O efeito da diminuição da porosidade aparente juntamente com a diminuição da densidade aparente em altas temperaturas está associado à formação de porosidade fechada durante a sinterização. Durante a sinterização os poros abertos vão sendo eliminados restando no final os poros fechados. Estes poros não se comunicam com a superfície do material impedindo a absorção de água, levando a uma diminuição da absorção de água e redução da porosidade aparente com o aumento da temperatura. Com o aumento da temperatura ocorre também a expansão dos gases presentes nos poros fechados, o que leva a formação de poros maiores do que em temperaturas inferiores diminuindo a densidade. A origem dos gases aprisionados nos poros está associada ao ar preso nos poros fechados, à perda de hidroxilas $(\mathrm{OH})$ dos cristais de caulinita $\mathrm{e}$ à liberação de oxigênio devido à decomposição do óxido férrico $\left(\mathrm{Fe}_{2} \mathrm{O}_{3}\right.$ para $\left.\mathrm{Fe}_{3} \mathrm{O}_{4}\right)[15,16]$.

A comparação da densidade aparente entre composições não é viável em virtude da diferença de densidade do resíduo de rochas ornamentais e do feldspato e suas diferentes porcentagens nas composições.

Pode-se observar que o resíduo de rochas ornamentais provoca a formação de uma fase líquida com menor viscosidade que o feldspato e em menor temperatura, uma vez que, na temperatura de $1200^{\circ} \mathrm{C}$ as composições que possuem resíduo já apresentam alta densidade, baixa absorção de água e porosidade e nas temperaturas de sinterização de $1250^{\circ} \mathrm{C}$, as composições que continham resíduo tiveram deformação piroplástica enquanto que a composição sem resíduo não apresentou esse fenômeno. Esse fato está associado à composição química do resíduo de rochas ornamentais, que possui na sua composição uma grande quantidade de óxidos fundentes como $\mathrm{CaO}, \mathrm{K}_{2} \mathrm{O}$ e $\mathrm{Fe}_{2} \mathrm{O}_{3}$. Isso faz com que a temperatura da fase líquida formada seja mais baixa, baixando a temperatura de queima e reduzindo o intervalo de queima da porcelana $[15,16]$.

A presença do resíduo de rochas ornamentais nas composições permitiu que a temperatura de sinterização fosse diminuída quando comparada com a composição sem resíduo, porém, reduziu o intervalo de queima, pois, como pode ser observado na Figura 6 (a), a densidade para as composições 1, 2 e 3 atinge um máximo na temperatura de $1200^{\circ} \mathrm{C}$ e com o aumento da temperatura para $1250^{\circ} \mathrm{C}$, ela é diminuída acentuadamente. A sinterização para intervalos pequenos de temperatura requer fornos mais avançados para uma manutenção de temperatura mais estável, o que pode dificultar a viabilidade da substituição do feldspato por resíduo de rochas ornamentais em grandes quantidades em formulações de porcelanas tradicionais.

O aumento de resistência mecânica com o aumento da temperatura, apresentado na Figura 6 (b), é observado para todas as composições estudadas. Este aumento na resistência mecânica está relacionado com o aumento da densidade com a temperatura. Os resultados mostram também que ocorre um aumento mais significativo na resistência mecânica na composição em que todo o feldspato é substituído por resíduo (composição 3) na temperatura de sinterização de $1200^{\circ} \mathrm{C}$. Este comportamento pode ser explicado pela mulita presente nessas estruturas, e pela tensão compressiva na fase vítrea, sendo que esta tensão é provocada pela diferença no coeficiente de expansão térmica entre a matriz (fase vítrea) e os grãos dispersos nesta matriz, como o quartzo, mulita e cristobalita. A presença dessas fases é evidenciada pela difração de raios X das composições sinterizadas a $1200^{\circ} \mathrm{C}$, apresentadas na Figura 7. Observa-se que, todas as composições apresentam as fases cristalinas da mulita e quartzo, sendo que, nas composições 2 e 3 , com resíduo de rochas ornamentais, há ainda a formação da fase cristobalita, e a presença de pequenos picos de anortita, oriundos do resíduo das rochas ornamentais.

A presença de cristobalita em vez de quartzo geralmente aumenta a resistência mecânica, apesar de a cristobalita apresentar uma transformação com variação volumétrica maior no resfriamento do que o quartzo. Isso pode ser explicado por três razões: o diâmetro da partícula da cristobalita tende a ser bem menor que do quartzo porque a cristobalita cristaliza em uma fase vítrea ou provém da conversão direta do quartzo; a cristobalita se forma à custa do quartzo, reduzindo a quantidade do quartzo e a faixa de temperatura de conversão da cristobalita é entre 225 e $250^{\circ} \mathrm{C}$, bem menor que a temperatura de $573^{\circ} \mathrm{C}$ do quartzo, isso leva a um menor tensionamento durante o resfriamento. 


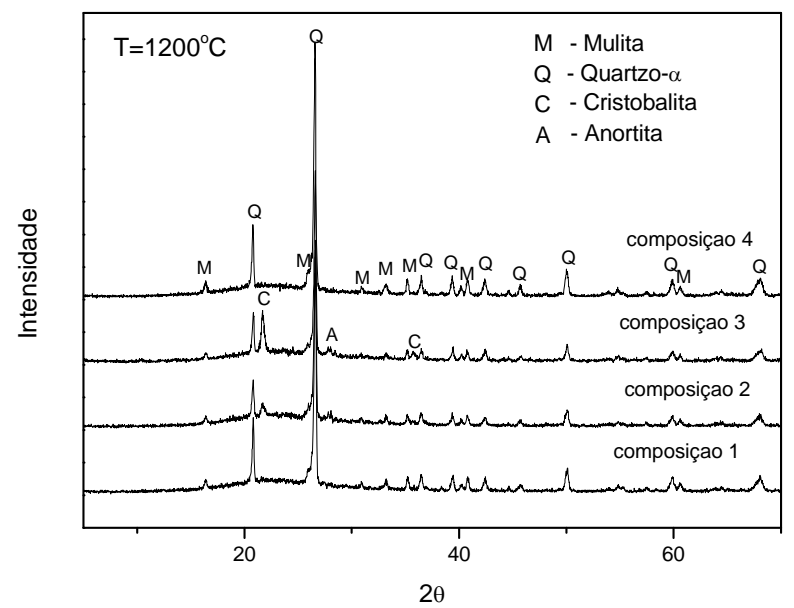

Figura 7: Difração de raios X de todas as composições sinterizadas a $1200^{\circ} \mathrm{C}$.

Por meio das imagens obtidas por microscopia eletrônica de varredura, Figuras 8 e 9, juntamente com a difração de raios $\mathrm{X}$, Figura 7, foi possível a determinação das diferentes fases presentes nas microestruturas. As micrografias das composições 1, 2, 3 e 4 sinterizadas a $1200^{\circ} \mathrm{C}$, observadas na Figura 8 , mostram a presença de mulita primária, mulita secundária e grãos de quartzo disperso numa matriz vítrea. A mulita primária se apresenta na forma de um agregado de cristais de pequena dimensão e é formada a partir da argila caulinítica e a mulita secundária se apresenta na forma de agulhas prismáticas, formada na região da fase vítrea. É possível observar que os grãos de quartzo se apresentam com contornos arredondados e possuem um contorno formado pela fase vítrea ao redor da partícula, devido à sua dissolução parcial do quartzo na fase vítrea. Observa-se também que ao redor do mesmo não existe a formação de fases cristalinas, provavelmente devido à alta concentração de sílica dissolvida no vidro. Este fenômeno ao redor do grão de quartzo chama-se de anel de dissolução.
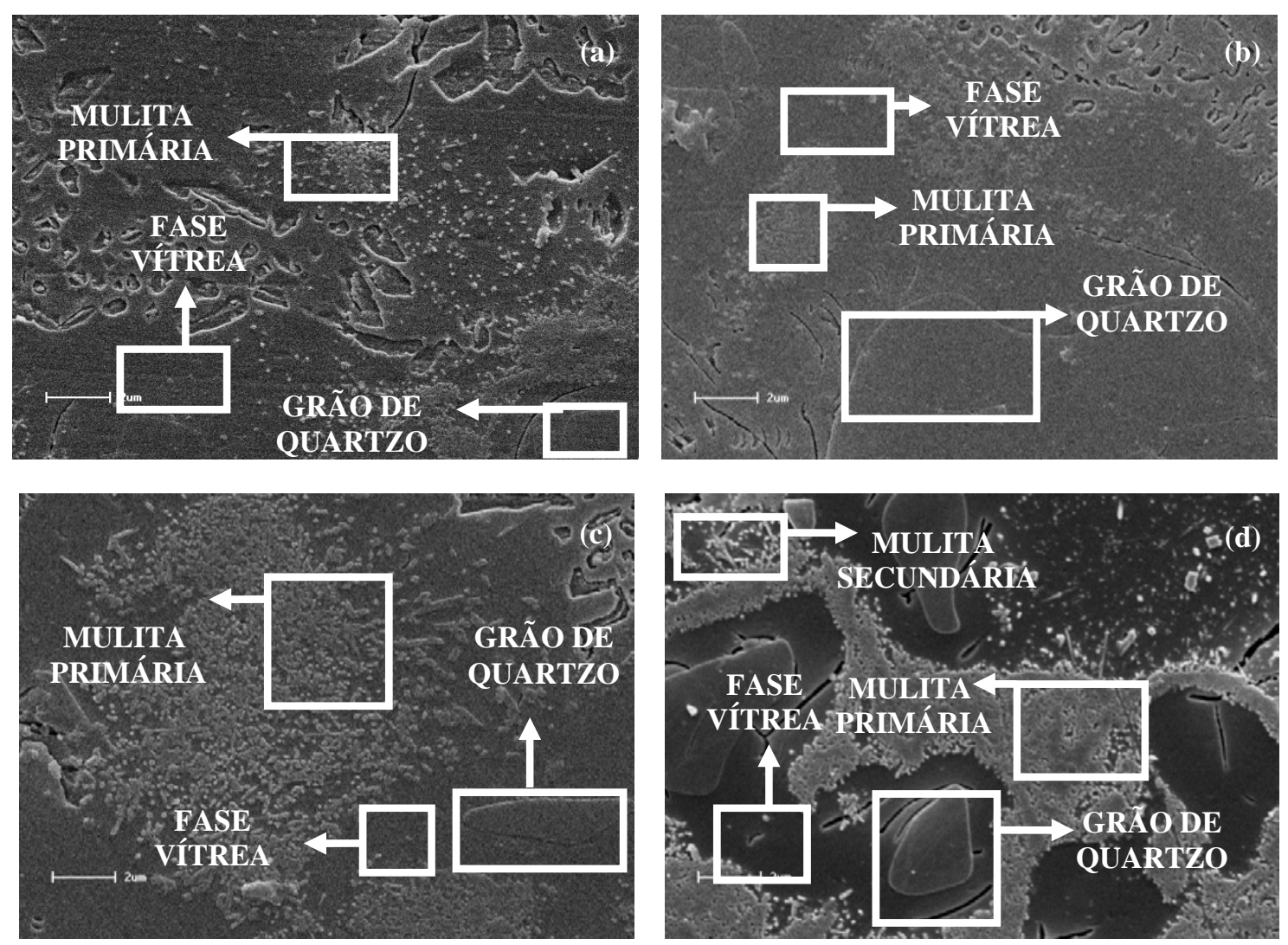

Figura 8: Micrografias das porcelanas sinterizadas a $1200^{\circ} \mathrm{C}$ : (a) composição 1; (b) composição 2; (c) composição 3; e composição (4). 
As trincas presentes nas micrografias nos contornos de fase estão ligadas com os coeficientes de expansão térmica; esse trincamento em torno das partículas ocorre quando as fases se contraem mais que a matriz, isto acontece com partículas de quartzo e matriz vítrea feldspática, as tensões geradas e também o trincamento se tornam mais severos devido à transformação do quartzo $(\beta \rightarrow \alpha)$ durante o resfriamento, o tamanho das partículas é um fator de extrema importância no desenvolvimento das trincas. Estas trincas tornam-se mais pronunciadas devido ao ataque ácido utilizado para revelar as demais fases.

Na Figura 9 observa-se um conjunto de micrografias de todas as composições (1, 2, 3 e 4) nas temperaturas de sinterização $1100^{\circ} \mathrm{C}, 1150^{\circ} \mathrm{C}$ e $1200^{\circ} \mathrm{C}$, permitindo avaliar a evolução do processo de sinterizacão.

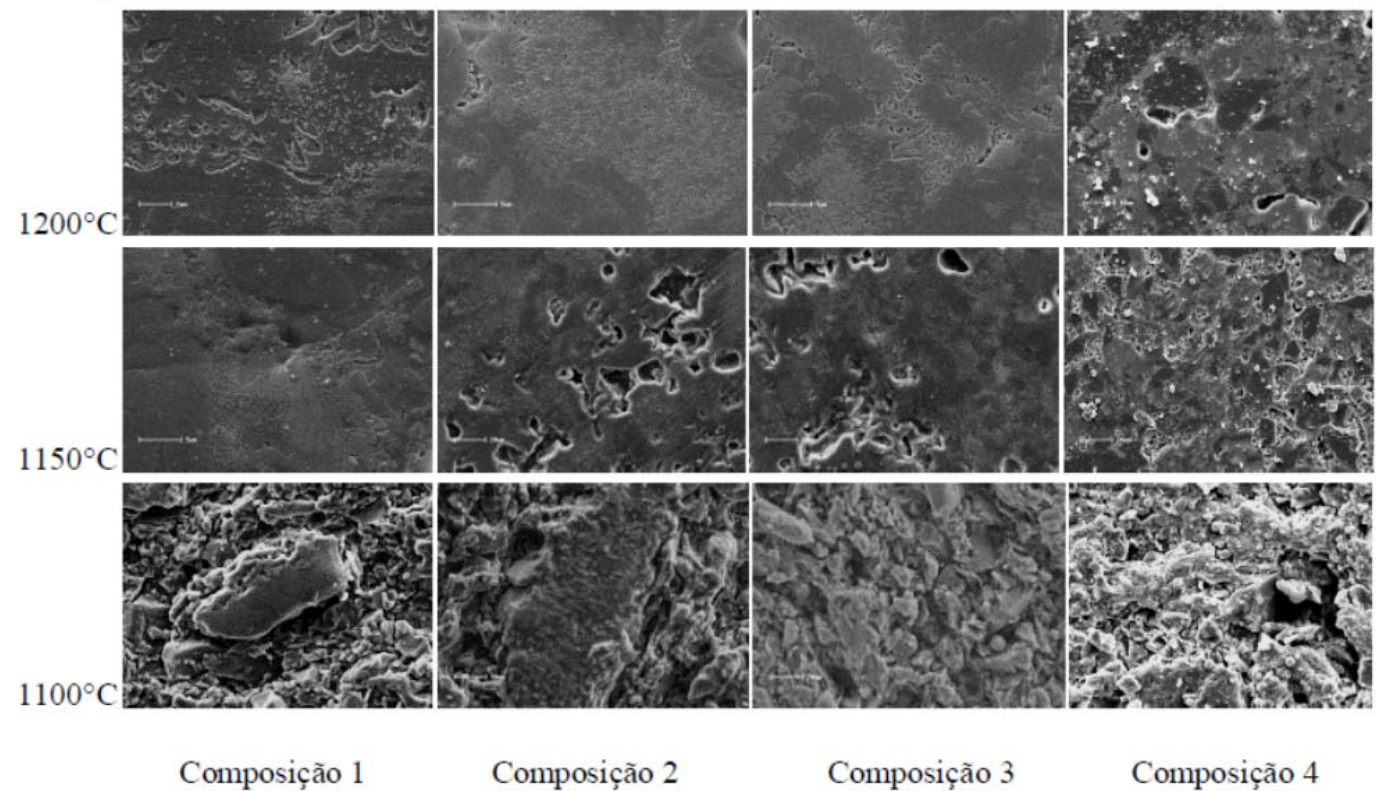

Figura 9: Micrografia de composições $1,2,3$ e 4, nas temperaturas de sinterização $\left(1100^{\circ} \mathrm{C}, 1150^{\circ} \mathrm{C}\right.$ e $\left.1200^{\circ} \mathrm{C}\right)$.

Na primeira linha de micrografias em que são apresentadas as composições sinterizadas a $1100^{\circ} \mathrm{C}$ é observada alta porosidade juntamente com a ausência de fases bem definidas o que indica que a sinterização não ocorreu completamente a essa temperatura. Pode-se observar a forma das partículas iniciais ainda definidas.

$\mathrm{Na}$ temperatura de $1150^{\circ} \mathrm{C}$ pode-se observar a formação do líquido, onde ocorreu o molhamento das partículas sólidas, evidenciado pela formação de pescoços entre as partículas, o líquido aproximou as partículas por força de capilaridade, iniciando o processo de densificação. É possível observar grãos de quartzo- $\alpha$ juntamente com pequenas quantidades de mulita na estrutura e o começo de definição das fases na microestrutura. Nessa microestrutura, observa-se um contorno de fases mais definido, além de uma quantidade muito inferior de poros em relação à composição sinterizada a $1100^{\circ} \mathrm{C}$.

Na temperatura de $1200^{\circ} \mathrm{C}$, pode-se observar a presença de mulita primária e grãos de quartzo bem definidos na microestrutura em todas as composições estudadas. A semelhança das micrografias da composição base com as composições que sofreram substituição por resíduos, juntamente com a semelhança dos picos da difração para a temperatura de $1200^{\circ} \mathrm{C}$ (Figura 7) e os resultados mecânicos (Figura 6 b) indicam que não houve grandes variações das propriedades da porcelana com a adição do resíduo, somente uma diminuição do intervalo de sinterização durante o processo.

\section{CONCLUSÕES}

Com base nos resultados obtidos pelas caracterizações mecânicas e físicas, conclui-se que é viável a substituição parcial do feldspato por resíduo de polimento de rochas ornamentais.

A substituição total ou parcial do feldspato por resíduo de polimento de rochas ornamentais provocou a diminuição da temperatura de sinterização dessas porcelanas. Este efeito permite diminuir os gastos de energia durante a sinterização. 
O intervalo de temperaturas de sinterização observado para a composição 3 , onde ocorreu a substituição total do feldspato por resíduo de polimento de rochas ornamentais, foi menor em relação à composição base, composição 4. Este efeito pode encarecer o processo, pois requer fornos com maior controle de temperatura para atingir os valores de porosidade desejados.

\section{AGRADECIMENTOS}

Ao LIMAC (Laboratório Interdisciplinar de Materiais Cerâmicos) da Universidade Estadual de Ponta Grossa (UEPG).

\section{BIBLIOGRAFIA}

[1] RAUP-PEREIRA, F. Valorização de resíduos industriais como fonte alternativa mineral: composições cerâmicas e cimentíceas. Tese de D.Sc., Universidade de Aveiro/Departamento de Engenharia Cerâmica e do Vidro, Aveiro, Portugal, 2006.

[2] MONFORT, E., ENRIQUE, J. E. "Economia Energética e Vantagens Meio ambientais da Reutilização de Resíduos", Cerâmica Industrial, v. 01, n.04/05, pp.14-20, Ago/Dez, 1996.

[3] GONÇALVES, J. P. Utilização do resíduo de corte de granito como adição para produção de Concretos. Dissertação de M.Sc., Universidade Federal do Rio Grande do Sul/Programa de Pós-Graduação em Engenharia Civil, Porto Alegre, 2000.

[4] MOURA, W. A., LEITE, M. B. "Estudo da viabilidade da produção de blocos com utilização de resíduo de serragem de rochas ornamentais para alvenaria de vedação" Revista Escola de Minas, v.64, n. 02, pp. 147154, abr/jun, 2011.

[5] MOURA, W. A., GONÇALVES, J. P., LEITE, R. S., "Utilização do resíduo de corte de mármore e granito em argamassas de revestimento e confecção de lajotas para piso", Revista da Universidade Estadual de Feira de Santana, n. 6, pp. 49-61, jan./jun. 2002.

[6] RODRIGUEZ, A. M. Resíduo de granito e outras matérias-primas para a fabricação de grés porcelanato. Dissertação de M.Sc., Universidade Estadual de Ponta Grossa, Ponta Grossa, 2004.

[7] FREIRE, L. C., QUEIROZ, J. P. C., CARANASSIOS, A. "Utilização de Resíduos Oriundos do Desdobramento de Rochas Ornamentais Para Confecção de Blocos Paisagísticos”, In: XVII Jornada de Iniciação Científica - CETEM. 126587, pp. 137- 143, jul. 2009

[8] ALVES, J. O. Processo de reciclagem da escória de aciaria e do resíduo de corte de granito visando a produção de lã mineral. Dissertação de M.Sc, UFOP - CETEC - UEMG/ REDEMAT Rede Temática em Engenharia de Materiais, Ouro Preto, MG, 2008.

[9] TORRES, P., FERNANDES, H. R., OLHERO, S., et al, "Incorporation of wastes from granite rock cutting and polishing industries to produce roof tiles", Journal of the European Ceramic Society, "http://www.sciencedirect.com/science/journal/09552219/29/1" lo "Go to table of contents for this volume/issue", pp. 23-30, Jan. 2009.

[10] PEREZ, E. J. A., TERRADAS, R., MANENT, M. R., et al, "Inertization of industrial wastes in ceramic materials", Industrial Ceramics, v.1, n.16, pp. 7-10, 1996.

[11] VITÓRIASTONEFAIR, http://www.vitoriastonefair.com.br/site/2013/pt/setor, acessado em outubro de 2014.

[12] SILVA, A. A. A. "Gestão de resíduos na indústria de rochas ornamentais, com enfoque para lama abrasiva”, In: VII Congresso Nacional de Excelência em Gestão, pp. 1-19, Rio de Janeiro, ago. 2011.

[13] NITES-Núcleo Regional de Informação Tecnológica do Espírito Santo, "Desperdício na Indústria de Mármore e Granito. Rochas de Qualidade", ed.118, Jul/Ago/Set. 1994.

[14] SILVA, J. B., HOTZA, D., SEGADÃES, A. M., et al.; "Incorporação de lama de mármore e granito em massas argilosas" Cerâmica, vol. 51, pp. 325-330, 2005.

[15] CHINElatTO, A. L., SOUZA, D. P. F. "Porcelanas elétricas aluminosas: Parte I - Revisão da Literatura", Cerâmica, v.50, pp.62-68, 2004.

[16] BRAGANÇA, S.R., BERGMANN, C.P. "Aspectos teóricos e práticos sobre a resistência mecânica de porcelanas", Cerâmica, v.50, pp.145-155, 2004. 